\title{
The Role of the Striatum in Compulsive Behavior in Intact and Orbitofrontal-Cortex-Lesioned Rats: Possible Involvement of the Serotonergic System
}

\author{
Eduardo A Schilman', Oded Klavir', Christine Winter ${ }^{2}$, Reinhard Sohr ${ }^{3}$ and Daphna Joel*, \\ 'Department of Psychology, Tel Aviv University, Tel Aviv, Israel; '2Department of Psychiatry and Psychotherapy, Charité Campus Mitte, University \\ Medicine Berlin, Berlin, Germany; ${ }^{3}$ Institute of Pharmacology and Toxicology, Charité Campus Mitte, University Medicine Berlin, Berlin, Germany
}

\begin{abstract}
In the signal attenuation rat model of obsessive-compulsive disorder (OCD), 'compulsive' behavior is induced by attenuating a signal indicating that a lever-press response was effective in producing food. We have recently found that lesions to the rat orbitofrontal cortex (OFC) led to an increase in compulsive lever-pressing that was prevented by systemic administration of the selective serotonin reuptake inhibitor paroxetine, and paralleled by an increase in the density of the striatal serotonin transporter. This study further explored the interaction between the OFC, the striatum, and the serotonergic system in the production of compulsive lever-pressing. Experiment I revealed that OFC lesions decrease the content of serotonin, dopamine, glutamate, and GABA in the striatum. Experiment 2 showed that intrastriatal administration of paroxetine blocked OFC lesion-induced increased compulsivity, but did not affect compulsive responding in intact rats. Experiments 3 and 4 found that pre-training striatal lesions had no effect on compulsive lever-pressing, whereas post-training striatal inactivation exerted an anticompulsive effect. These results strongly implicate the striatum in the expression of compulsive lever-pressing in both intact and OFC-lesioned rats. Furthermore, the results support the possibility that in a subpopulation of OCD patients a primary pathology of the OFC leads to a dysregulation of the striatal serotonergic system, which is manifested in compulsive behavior, and that antiobsessional/anticompulsive drugs exerts their effects, in these patients, by normalizing the dysfunctional striatal serotonergic system.
\end{abstract}

Neuropsychopharmacology (2010) 35, 1026-1039; doi:I0.1038/npp.2009.208; published online I3 January 2010

Keywords: signal attenuation; caudate-putamen; extinction; inactivation; paroxetine

\section{INTRODUCTION}

Obsessive-compulsive disorder (OCD) is a psychiatric affliction with a lifetime prevalence of $1-3 \%$, characterized by recurrent, intrusive, and unwanted thoughts (obsessions) and/or repetitive ritualistic behaviors (compulsions, American Psychiatric Association, 1994). Three neural systems figure out most prominently in the pathophysiology of OCD, the serotonergic system, the orbitofrontal cortex (OFC), and the striatum (for review, see Stein, 2000; Friedlander and Desrocher, 2006).

Dysregulation of the serotonergic system has been suggested primarily on the basis of the effectiveness of serotonin reuptake inhibitors in alleviating obsessions and compulsions in patients (Zohar and Insel, 1987; Zohar et al, 1992), and has received further support from neurobio-

*Correspondence: Professor D Joel, Department of Psychology, Tel Aviv University, Ramat Aviv, Tel Aviv 69978, Israel,

Tel: +972 3640 8996, Fax: +972 3640 9547,

E-mail: djoel@post.tau.ac.il

Received I July 2009; revised 12 November 2009; accepted 12 November 2009 logical and pharmacological data (for review see Sasson and Zohar, 1996; Stein, 2000). In parallel, the results of neuroimaging studies in OCD patients have implicated dysfunction of the OFC and of the striatum in the pathophysiology of OCD (for review see Saxena et al, 1998; Stein, 2000). The metabolic activity of these two regions was found to be higher in OCD patients compared to healthy controls, to increase during symptom provocation, and to decrease after a successful treatment with selective serotonin reuptake inhibitors (SSRIs; Baxter et al, 1992; Benkelfat et al, 1990; Breiter et al, 1996; Cottraux et al, 1996; Insel, 1992; McGuire et al, 1994; Rauch et al, 1994; Saxena et al, 1999; Swedo et al, 1992). Although the serotonergic system, the $\mathrm{OFC}$, and the striatum are interconnected, the specific abnormality of these regions, as well as the ways in which they interact to produce obsessions and compulsions, is unknown.

We have recently studied the interaction between these three neural systems in the production of compulsive behavior using the signal attenuation rat model of OCD. This model was developed on the basis of the theoretical proposition that compulsive behaviors result from a deficit 
in the feedback associated with the performance of normal goal-directed responses (for review, see Otto, 1992; Szechtman and Woody, 2004). In the model, the goal-directed behavior is lever-pressing for food. To manipulate the feedback associated with making a response, we use the following strategy: rats are first trained to lever-press for food, whose delivery is accompanied by a stimulus that had been previously paired with food. In this manner the stimulus is established as a feedback cue which signals that the leverpress response was effective in producing food. The 'signaling' property of the stimulus is then attenuated by repeatedly presenting the stimulus without food (without the rat emitting the lever-press response). Finally, the effects of signal attenuation on lever-press responding are assessed under extinction conditions, that is, pressing the lever results in the presentation of the stimulus but no food is delivered. We showed that signal attenuation leads to excessive lever-pressing that is not accompanied by an attempt to collect a reward. We have named this behavior 'compulsive' lever-pressing because it may be analogous to the excessive and unreasonable behavior seen in OCD. Compulsive lever-pressing is abolished by the SSRIs fluoxetine, paroxetine, and fluvoxamine, but not by the anxiolytic drug, diazepam, the antipsychotic, haloperidol, or the tricyclic antidepressant, desipramine (Joel and Avisar, 2001; Joel and Doljansky, 2003; Joel et al, 2004). These findings are in accordance with the differential efficacy of these drugs in alleviating obsessions and compulsions in OCD patients (Zohar et al, 1992; Piccinelli et al, 1995; Dolberg et al, 1996). Compulsive lever-pressing is also sensitive to manipulations of the OFC (FlaisherGrinberg et al, 2008; Joel et al, 2005a, b; Joel and Klavir, 2006) and of the dopaminergic and serotonergic systems (Flaisher-Grinberg et al, 2008; Joel et al, 2001; Joel and Doljansky, 2003), in line with different lines of evidence implicating these systems in the pathophysiology of OCD (for review see Stein, 2000; Aouizerate et al, 2004).

We have recently found that lesions to the rat OFC increased compulsive lever-pressing, and that this increase was prevented by systemic administration of the SSRI paroxetine, and paralleled by an increase in the density of the striatal serotonin transporter (Joel et al, 2005a, b). These results raise the possibility that in a subpopulation of OCD patients, the observed association between OCD and a dysfunction of the OFC, the striatum and the serotonergic system, reflects pathology of the OFC that leads to a dysregulation of the striatal serotonergic system which is manifested in compulsive behavior (Joel et al, 2005a).

The aim of this study was to further explore the interaction between the OFC, the striatum, and the serotonergic system in the production of compulsive behavior in the signal attenuation model. Experiment 1 assessed the biochemical changes in the striatum that follow lesions to the OFC. Experiment 2 showed that the OFC lesion-induced increase in compulsive lever-pressing can be blocked by intrastriatal administration of the SSRI paroxetine. The OFC lesions in this study are similar to those in our previous reports (Joel et al, 2005a, b), and are confined mainly to the lateral, ventrolateral, and ventral orbital regions, according to the terminology of Van de Werd and Uylings (2008). The striatal region targeted in Experiment 2, as well as in Experiments 3 and 4, is a ventromedial region of the dorsal striatum (ie, of the caudate-putamen) that is innervated by the ventral and ventrolateral orbital regions (Schilman et al, 2008), as well as by the dorsal part of the prelimbic cortex, whose terminal field extends also more dorsally in the striatum, and to a much lesser extent by the ventral prelimbic cortex (Berendse et al, 1992).

Experiments 3 and 4 tested the effects of pre-training striatal lesion (Experiment 3) and post-training striatal inactivation (Experiment 4) in otherwise intact rats on compulsive lever-pressing (in Experiment 4, we chose to use pharmacological inactivation of the striatum rather than a post-training lesion, because only using the former procedure it is possible to manipulate the striatum without interfering with the time schedule of the behavioral procedure (a lesion requires several days of recovery from surgery before behavioral testing can be resumed)). Because Experiments 3 and 4 are the first to test the involvement of the striatum in compulsive behavior as defined in the signal attenuation model, the effects of the two manipulations were assessed in rats undergoing an extinction test of leverpress responding that was preceded by signal attenuation (the post-training signal attenuation (PTSA) procedure), and in rats undergoing a control procedure in which the extinction test was not preceded by signal attenuation (the 'regular extinction' (RE) procedure). This design enables differentiation between the effects of signal attenuation and of extinction per se. In short, a manipulation-induced effect on compulsive responding is evidenced in a change in the number of excessive lever-presses that are not followed by magazine entry (ELP-U) in the PTSA procedure only, whereas a manipulation-induced effect on extinction is manifested in a change in the number of excessive leverpresses that are followed by magazine entry (ELP-C) in both the PTSA and the RE procedures (for a detailed discussion see Joel, 2006).

\section{MATERIALS AND METHODS}

\section{Subjects}

Male Sprague-Dawley rats (Harlen, Jerusalem, Israel), approximately 12 weeks old, were housed individually under reversed cycle lighting (lights on: 1900-0700 hours). A 22-h food restriction schedule with freely available water was started at the beginning of the experiment. All experimental protocols conformed to the guidelines of the Institutional Animal Care and Use Committee of Tel Aviv University, Israel.

\section{Apparatus and Behavioral Procedures}

Behavioral testing was conducted in operant chambers (Campden Instruments, Loughborough, UK) equipped with a 3 W houselight; a Sonalert module (Model SC 628; Mallory Sonalert, Indianapolis, IN) that could produce an $80 \mathrm{~dB}$, $2.8 \mathrm{kHz}$ tone; and two retractable levers on either side of a food magazine (fitted with a $3 \mathrm{~W}$ magazine light), into which $45 \mathrm{mg}$ Noyes precision food pellets (Noyes, Sandown Chemical, Hampton, UK) could be delivered. Access to the food magazine was through a hinged panel, the opening of which activated a microswitch. Equipment programming and data recording were computer-controlled. Before the 
beginning of training, rats were handled for about $2 \mathrm{~min}$ daily for 5 days. On the last 3 days of handling, rats were acquainted to the food pellets that would later serve as reinforcement for operant training.

Post-training signal attenuation. The PTSA procedure included four stages. The organization of a trial of each of these stages is presented in Figure 1.

Stage 1: magazine training: Rats were trained to collect food pellets from the food magazine. On each trial, a single food pellet was dropped into the food magazine simultaneous with the onset of the magazine light and tone (the stimulus). The stimulus was turned off after the rat's head entered the food magazine or after $15 \mathrm{~s}$ had elapsed, and a $30 \mathrm{~s}$ intertrial interval began. Rats were given three sessions over 3 consecutive days, each lasting until a rat completed 30 collected trials (magazine entry during stimulus presentation) or 40 trials.

Stage 2: lever-press training: On the following day, rats received a session of pre-training using a free-operant schedule. The houselight was on, and the two levers were present in the operant box throughout the entire session. Responding on one of the levers (reinforced lever, RL) resulted in the delivery of a food pellet, accompanied by the presentation of the stimulus. The stimulus was turned off after the rat's head entered the food magazine or after $15 \mathrm{~s}$ from the rat's first lever-press had elapsed. The lever designated as RL was counterbalanced over subjects and remained the same for each rat over the entire experimental procedure. Each rat was trained until it completed 30 trials (ie, pressed the lever and inserted its head into the food magazine during stimulus presentation). Next, rats received three sessions (one session per day) of lever-press training in a discrete-trial procedure (Figure 1). On each trial, both levers were inserted into the chamber. Responding on the RL resulted in the delivery of a food pellet into the magazine, accompanied by the presentation of the stimulus. The levers were retracted and the stimulus was turned off after the rat's head entered the food magazine or after $15 \mathrm{~s}$ from the rat's first lever-press had elapsed $(10 \mathrm{~s}$ on the second lever-press training session and on subsequent sessions). Further lever-presses on the RL as well as responding on the other lever (nonreinforced lever, NRL) had no programmed consequences but were recorded. Each trial was followed by a $30 \mathrm{~s}$ intertrial interval. Each rat was trained until it completed 40 trials or a total of 60 trials. In addition to the number of completed trials, the number of trials on which the rat did not press the RL (unpressed trials) and the number of trials on which the rat pressed the RL without inserting its head into the food magazine (uncompleted trials) were recorded. As in previous studies, the measures of prime interest were the number of leverpresses on the RL after the first response (extra leverpresses, ELP) in uncompleted trials (that is, ELP not followed by magazine entry; ELP-U) and ELP in completed trials (that is, ELP followed by magazine entry, ELP-C).

Stage 3: signal attenuation: On the following 3 days, with the levers retracted, rats were exposed to the presentation of the stimulus as in the magazine training sessions, but no food was delivered to the food magazine (note that the food dispenser rotated as in the other stages, but it was empty, and therefore no pellet was delivered, Figure 1). Rats received 30 such trials on each day. The number of collected trials was recorded. Rats that had more than 14 collected trials on the last day of signal attenuation
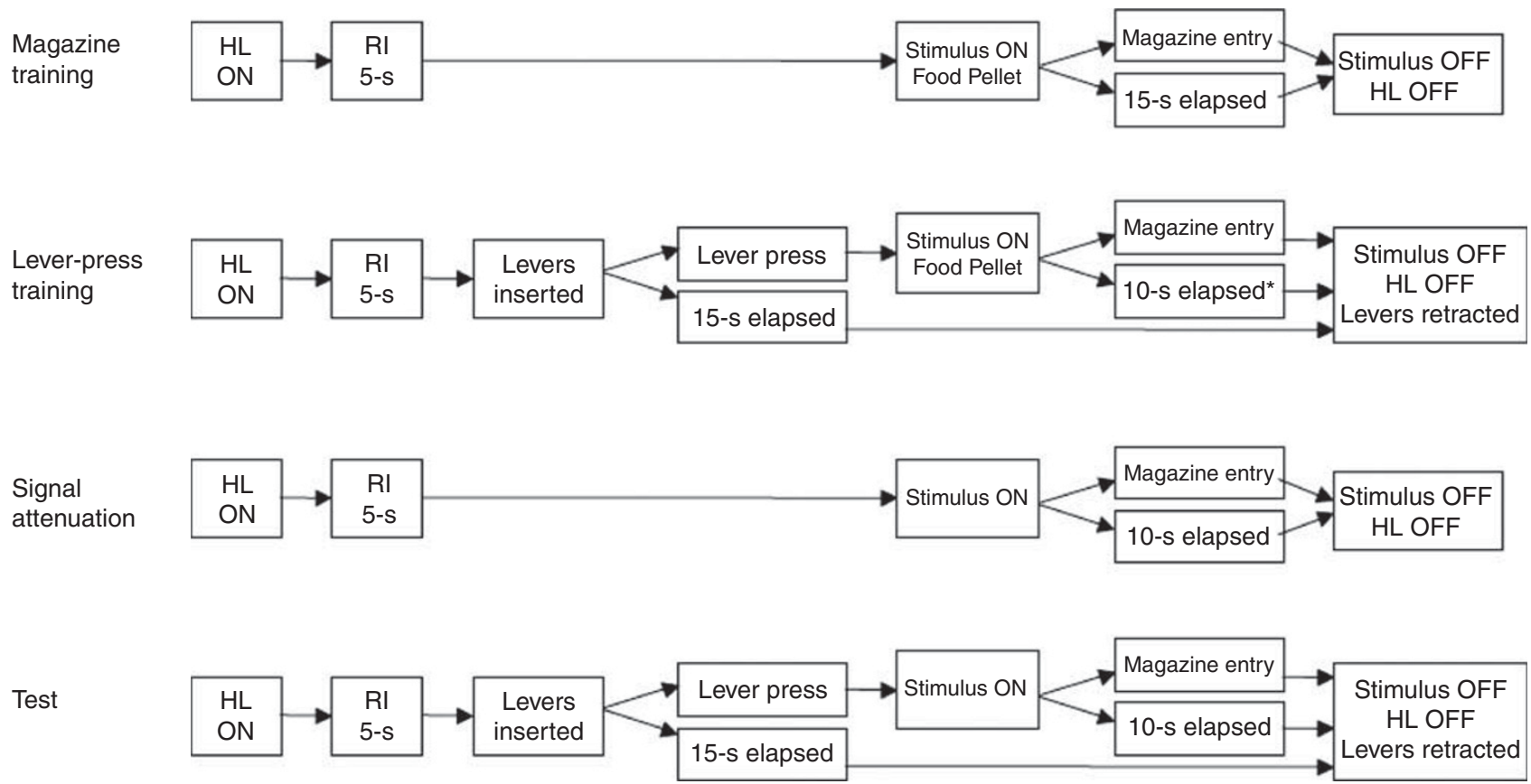

Figure I A schematic diagram of the organization of a trial in each of the different training stages of the post-training signal attenuation procedure. $\mathrm{HL}$, houselight; RI, random interval; *on the first day of lever-press training (day 5) this time limit was $15 \mathrm{~s}$. 
were returned to the test chamber at the end of the day for an additional session.

Stage 4: test: On the following day, rats were trained as in the lever-press training sessions, except that no food was delivered to the food magazine (ie, pressing the lever resulted in the presentation of the stimulus only, Figure 1). The session lasted for 50 trials. The behavioral measures recorded were the same as in the lever-press training stage. We define compulsive lever-pressing as the number of ELP$\mathrm{U}$ in the test stage of the PTSA procedure. It should be noted that the mean number of ELP-U and ELP-C may vary between experiments, and that therefore meaningful comparisons can be made only within experiments and not between experiments.

Regular extinction. Rats were run exactly as in the PTSA procedure, with the exception that they did not undergo the signal attenuation stage. On these days, rats were brought to the laboratory and left in their home cages for a period equivalent to the average duration of the signal attenuation stage.

\section{Surgery}

Rats received $3 \mathrm{mg}$ diazepam and were anesthetized $10 \mathrm{~min}$ later with an intraperitoneal injection of Avertin $(10 \mathrm{ml} / \mathrm{kg})$. OFC lesions: bilateral 31-gauge cannulae were vertically lowered into the brain through holes drilled in the skull. Two infusions per hemisphere of $0.3 \mu \mathrm{l}$ NMDA (Sigma Chemicals, Rehovot, Israel; diluted with phosphate-buffered saline (PBS) to a final $\mathrm{pH}$ of 7.4 and a concentration of $0.12 \mathrm{M}$ ) were delivered at a constant rate over $3 \mathrm{~min}$ at the following coordinates (Paxinos and Watson, 2005): $3.7 \mathrm{~mm}$ anterior to bregma (A-P), $2.4 \mathrm{~mm}$ lateral to the midline (M-L), and $3.3 \mathrm{~mm}$ ventral to dura $(\mathrm{D}-\mathrm{V})$. The cannulae were left in place for additional $2 \mathrm{~min}$, to reduce upward diffusion of the solution. OFC sham lesion: sham-operated rats underwent the same surgical procedure, but $0.3 \mu \mathrm{l}$ PBS was injected instead of NMDA. To prevent excitoconvulsive activity, we post-surgically administered all rats another intraperitoneal injection of $3 \mathrm{mg}$ diazepam. Cannulae implantation in the striatum: bilateral 26-gauge, stainless-steel guide cannulae (Bilaney, Düsseldorf, Germany) were stereotaxically implanted at the following coordinates (Paxinos and Watson, 2005): $0.2 \mathrm{~mm} \mathrm{A-P,} 2.5 \mathrm{~mm} \mathrm{M}-\mathrm{L}$, and $4.8 \mathrm{~mm} \mathrm{D}-\mathrm{V}$. These coordinates were chosen on the basis of a tracing study which showed that this region of the striatum is the main target area of projections from the OFC region lesioned in this study (Berendse et al, 1992; Schilman et al, 2008). Cannulae were fixed to the skull surface with stainless steel screws and dental acrylic cement (Pupko Dental, Tel Aviv, Israel). Removable stylets were placed in the guide cannulae and held in place with a screw-on dust cap. Striatal lesion: bilateral 31-gauge cannulae were vertically lowered into the brain through holes drilled in the skull. Two infusions per hemisphere of $0.6 \mu \mathrm{l}$ NMDA (Sigma Chemicals, Rehovot, Israel, diluted with PBS to a final $\mathrm{pH}$ of 7.4 and a concentration of $0.18 \mathrm{M}$ ) were delivered at a constant rate over $3 \mathrm{~min}$ at the following coordinates (Paxinos and Watson, 2005): $1.0 \mathrm{~mm} \mathrm{A-P,} 2.4 \mathrm{~mm} \mathrm{M}-\mathrm{L}$, and $5.0 \mathrm{~mm}$
$\mathrm{D}-\mathrm{V}$, and $0.0 \mathrm{~mm} \mathrm{~A}-\mathrm{P}, 2.5 \mathrm{~mm} \mathrm{M}-\mathrm{L}$, and $4.4 \mathrm{~mm} \mathrm{D}-\mathrm{V}$. The cannulae were left in place for additional $2 \mathrm{~min}$, to reduce upward diffusion of the solution. Striatal sham lesion: sham-operated rats underwent the same surgical procedures, except that no substance was infused. To prevent excitoconvulsive activity, we administered another intraperitoneal injection of $3 \mathrm{mg}$ diazepam post-surgically in all the rats. Rats were allowed at least 10 days of recovery with ad libitum food and water before behavioral training begun commenced.

\section{Microinjections}

Intrastriatal microinjections were prepared bilaterally using a dual-syringe infusion pump (CMA/100 microinjection pump; Medecin AB, Solona, Sweden). Rats were lightly anesthetized with isoflurane (Sigma Chemicals, Rehovot, Israel), the stylets were removed, and the injection needles (30 gauge) were inserted into the guide cannulae to protrude $1 \mathrm{~mm}$ below their tips. The drug was slowly delivered at a constant rate for $30 \mathrm{~s}$. At $1 \mathrm{~min}$ after the injection, the needles were slowly removed and replaced by the stylets. Experiment 2: paroxetine $(0.5 \mu \mathrm{l}$ per hemisphere dissolved in distilled water to a concentration of $0.75 \mu \mathrm{g} / \mu \mathrm{l}$; Unipharm, Ramat Gan, Israel) or vehicle (distilled water, $0.5 \mu \mathrm{l}$ per hemisphere) was injected $30 \mathrm{~min}$ before the test. Experiment 4: crystallized muscimol $(0.5 \mu \mathrm{l}$ per hemisphere dissolved in PBS to a concentration of $1 \mu \mathrm{g} / \mu \mathrm{l}$; Enco Diagnostics, Petach-Tiqva, Israel) was injected $50 \mathrm{~min}$ before the test. Rats in the sham group were lightly anesthetized with isoflurane (Sigma Chemicals, Rehovot, Israel) for an equivalent period of time but received no substance (to avoid potential mechanical damage or functional disruption caused by the infusion of a vehicle substance). The volume and concentration of muscimol injection were selected on the basis of a study that combined electrophysiology and autoradiography to estimate muscimol's diffusion distance and duration of effectiveness (Edeline et al, 2002), as well as previous behavioral studies that used muscimol for inactivation (Coutureau and Killcross, 2003; Izaki et al, 2001; Samson and Chappell, 2001).

\section{Histology}

Experiment 1: approximately 20 days following surgery, rats were decapitated and their brains were removed within seconds (this time point was chosen to match the time of the test on Experiment 2, as the rats in Experiment 1 did not undergo the behavioral procedure). Frozen coronal sections ( $1 \mathrm{~mm}$ thick) were prepared at the following coordinates with respect to bregma and as described previously (Winter et al, 2008a, b): A-P $(+1.7)-(+0.7),(+0.5)-(-0.5)$, and $(-1.8)-(-2.8)$ (coordinates according to Paxinos and Watson, 2005). Tissue samples of three different brain regions (nucleus accumbens, caudate-putamen anterior part, caudate-putamen posterior part) from both hemispheres were quickly isolated by a punch of $1 \mathrm{~mm}$ in diameter, snap-frozen in liquid nitrogen, and stored at $-80^{\circ} \mathrm{C}$ for further neurochemical analysis as described previously (Winter et al, 2008a, b). For verification of lesion extent, $40 \mu \mathrm{m}$ coronal sections of the OFC A-P +5.5 to + 
a

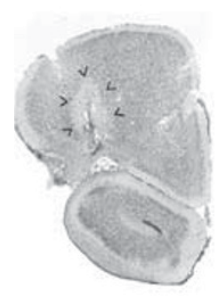

b

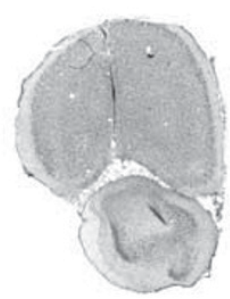

C

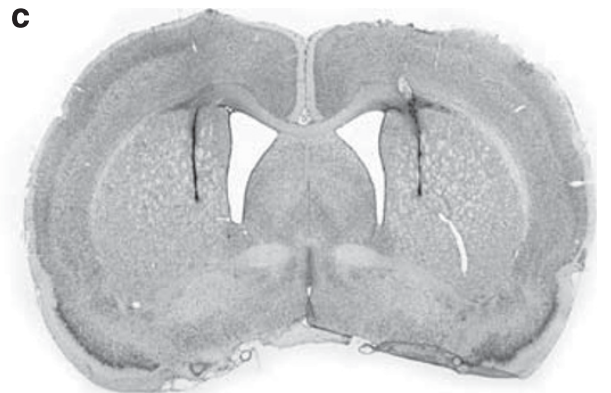

Figure 2 A photomicrograph of a ( $a, b)$ coronal section taken through the orbitofrontal cortex (OFC) from a representative OFC-lesioned rat (a, arrowheads indicate lesion location) and sham-operated rat (b), and (c) a coronal section taken through the striatum of a representative cannulaimplanted rat showing the cannula tract (Experiment 2).

$2.0 \mathrm{~mm}$ were mounted and processed for cresyl violet staining. For neurochemical analyses, tissue samples collected from the eight sham-operated and the eight OFC-lesioned rats were homogenized by ultrasonication in 20 volumes of $0.1 \mathrm{~N}$ perchloric acid at $4{ }^{\circ} \mathrm{C}$ immediately after collection through micropunches. Homogenates $(100 \mu \mathrm{l})$ were added to equal volumes of $1 \mathrm{~N}$ sodium hydroxide for measurement of protein contents. The remaining homogenates were centrifuged at $17000 \mathrm{~g}$ and $4{ }^{\circ} \mathrm{C}$ for $10 \mathrm{~min}$. Aliquot of the supernatants were added to equal volumes $(20 \mu \mathrm{l})$ of $0.5 \mathrm{M}$ borate buffer and stored at $-80^{\circ} \mathrm{C}$ for subsequent analyses of amino acids. The remaining supernatants were used for immediate measurement of monoamines and their metabolites. The levels of the monoamines dopamine and serotonin and their metabolites, dihydroxyphenylacetic acid and 5-hydroxyindole acetic acid, were measured by high-performance liquid chromatography with electrochemical detection as previously described (Felice et al, 1978; Sperk et al, 1981; Sperk, 1982). Glutamate, $\gamma$ amino butyric acid (GABA), and taurine were determined using methods described previously (Piepponen and Skujins, 2001). Briefly, amino acids were precolumn derivatized with $o$-phthalaldehyde-2-mercaptoethanol using a refrigerated autoinjector and then separated on a highperformance liquid chromatography column (ProntoSil C18 ace-EPS) at a flow rate of $0.6 \mathrm{ml} / \mathrm{min}$ and a column temperature of $40^{\circ} \mathrm{C}$. The mobile phase was $50 \mathrm{mM}$ sodium acetate $(\mathrm{pH} 5.7)$ in a linear gradient from 5 to $21 \%$ acetonitrile. Derivatized amino acids were detected by their fluorescence at $450 \mathrm{~nm}$ after excitation at $330 \mathrm{~nm}$. Comparisons between groups were performed by Student's $t$-test. Experiments 2-4: at 3 days after the completion of behavioral testing, all rats were overdosed with an intraperitoneal injection of Nembutal (sodium pentobarbital, $1 \mathrm{ml}$ / kg; Tiferet Hacarmel, Haifa, Israel) and perfused intracardially with $\mathrm{PBS}$ at room temperature for $2 \mathrm{~min}$ (flow rate $35 \mathrm{ml} / \mathrm{min}$ ), followed by $10 \%$ buffered formalin solution (approximately $4 \%$ formaldehyde) for $10 \mathrm{~min}$. The brains were removed and placed in $10 \%$ buffered formalin solution overnight, followed by $20 \%$ (wt/vol) sucrose solution for at least $24 \mathrm{~h}$. The brains were rapidly frozen and sectioned in the coronal plane at $40 \mu \mathrm{m}$ thickness and stained with Thionin (Holland Moran, Yahud, Israel), dehydrated, and coverslipped with Entellan (Merck, Darmstadt, Germany).

\section{RESULTS}

\section{Experiment 1: the Biochemical Changes Induced by OFC Lesions}

Most OFC lesions were similar in size. Neuronal loss and accumulation of glia cells were evident in LO, VLO, and VO. The only visible damage in sham-lesioned rats was the cannulae tracks toward the OFC (see Figure 2, which presents the OFC lesions of Experiment 2, which were similar in extent and location to those in Experiment 1). Table 1 presents the content ( $\mu$ Mol per g protein) of dopamine, serotonin, glutamate, GABA, and taurine in the anterior and posterior caudate-putamen and in the nucleus accumbens. As can be seen, of the regions assessed, the one most affected by the OFC lesion was the anterior caudateputamen, whereas no significant changes were observed in the nucleus accumbens. In the anterior striatum the content of dopamine, serotonin, GABA, and glutamate was reduced in OFC-lesioned rats to about $75 \%$ of the level measured in sham-operated rats (except for dopamine, which decreased to $82.5 \%$ of control levels). In the posterior striatum only serotonin content was decreased, but to a greater extent than in the anterior striatum (57\% of control levels). In addition, in both the anterior and the posterior striatum serotonin turnover was increased to about $150 \%$ of control levels.

\section{Experiment 2: the Effects of Intrastriatal Administration of Paroxetine in OFC-Lesioned Rats Undergoing the PTSA Procedure}

Anatomical. Figure 2 presents a photomicrograph of ( $a$ and $b$ ) a coronal section taken through the OFC from a representative OFC-lesioned rat (a) and sham-operated rat (b), and (c) a coronal section taken through the striatum. Figure $3 a$ presents a schematic reconstruction of the OFC lesion representing the minimal and the maximal extent of the damage common for all rats in the lesion group. Figure $3 b$ presents a schematic reconstruction of cannulae tips in the striatum. Most OFC lesions were similar in size. Neuronal loss and accumulation of glia cells were evident in LO, VLO, and VO. The only visible damage in sham-lesioned rats was the cannulae tracks toward the OFC. In most rats the cannulae tips were located in the region of the striatum 
Table I Content of Dopamine, Serotonin, Glutamate, and GABA in Different Striatal Subregions (Experiment I)

\begin{tabular}{|c|c|c|c|}
\hline Transmitter ( $\mu \mathrm{mol} / \mathrm{g}$ protein) & Controls & OFC-lesioned & Statistical significance $(p)$ \\
\hline \multicolumn{4}{|l|}{ Nucleus accumbens } \\
\hline Dopamine & $402.7 \pm 13.0$ & $384.3 \pm 16.7$ & \\
\hline DOPAC & $73.9 \pm 4.6$ & $74.2 \pm 4.1$ & \\
\hline (DOPAC/DA) & $0.2 \pm 0.03$ & $0.2 \pm 0.03$ & \\
\hline Serotonin & $19.0 \pm 1.1$ & $22.1 \pm 2.5$ & \\
\hline Glutamate & $59.7 \pm 3.9$ & $51.8 \pm 3.7$ & \\
\hline GABA & $15.8 \pm 1.0$ & $17.9 \pm 2.3$ & \\
\hline \multicolumn{4}{|l|}{ Caudate putamen anterior } \\
\hline $5-H I A A$ & $12.8 \pm 0.6$ & $12.5 \pm 1.0$ & \\
\hline $5-\mathrm{HIAA} / 5 \mathrm{HT}$ & $0.7 \pm 0.3$ & $1.0 \pm 0.2$ & 0.026 \\
\hline Glutamate & $78.2 \pm 1.9$ & $58.9 \pm 3.2$ & $<0.001$ \\
\hline GABA & $16.0 \pm 1.3$ & $12.2 \pm 0.9$ & 0.032 \\
\hline \multicolumn{4}{|l|}{ Caudate putamen posterior } \\
\hline Dopamine & $451.0 \pm 30.2$ & $457.2 \pm 39.5$ & \\
\hline DOPAC & $56.3 \pm 3.4$ & $57.8 \pm 4.4$ & \\
\hline (DOPAC/DA) & $0.1 \pm 0.02$ & $0.1 \pm 0.04$ & \\
\hline Serotonin & $32.9 \pm 2.4$ & $18.7 \pm 2.1$ & $<0.001$ \\
\hline
\end{tabular}

innervated by VLO and VO, and the only visible damage was the cannulae track toward the striatum. Four rats were excluded from the statistical analysis because there was no evidence of OFC lesion $(n=3)$ or because the cannulae were mislocated $(n=1)$.

Behavioral. Table 2 presents the number of rats allocated to this experiment, the number of rats that were excluded from the experiment, and the final number of rats in each group.

Magazine training: there were no differences between lesion and sham rats in the magazine training stage (data not shown, all F's $<1$ ). Lever-press training: there were no differences between OFC-lesioned and sham rats in the acquisition of lever-pressing (data not shown, all F's $<1$ ). On the last day of lever-press training, all rats achieved 40 completed trials, typically with no uncompleted trials and therefore with no ELP-U. From the second day of leverpress training, rats rarely pressed the NRL. Signal attenuation: there were no differences between OFC-lesioned and sham rats in the extinction of the compound stimulus, as reflected in the number of collected trials, in either the rate of extinction or in the performance level at the end of this stage (data not shown, all F's $<1$ ). Five (three OFC-lesioned and two sham-operated) rats underwent an extra session of signal attenuation after failing to reach criterion on the third day. All rats attained criterion after this additional session.

Test. Figures $4 \mathrm{a}$ and $\mathrm{b}$ present the mean number of ELP-C and ELP-U in the test. As described previously (Joel et al, $2005 \mathrm{a}, \mathrm{b})$, rats sustaining lesions to the OFC showed a higher number of ELP-U (compulsive lever-pressing), but not ELP-C, compared to sham-lesioned rats. Intrastriatal administration of paroxetine to OFC-lesioned rats blocked the lesion-induced increase in ELP-U, without affecting the number of ELP-C. Paroxetine had no effect on either ELP-C or ELP-U when administered into the striatum of sham rats (a Lesion $\times$ Drug analysis of variance (ANOVA) performed on the number of ELP-U yielded only a significant Lesion $\times$ Drug interaction, $\mathrm{F}(1,60)=6.75, p<0.012$; Lesion, $\mathrm{F}(1,60)=0.11$, NS; Drug, $\mathrm{F}(1,60)=0.07$, NS. Post hoc leastsignificant difference (LSD) comparisons compared the two vehicle-treated groups (ie, OFC-vehicle $v s$ sham-vehicle) as well as the paroxetine and vehicle groups within each lesion condition, and revealed a significant difference between the OFC-vehicle and sham-vehicle groups $(p=0.037)$, and between the OFC-vehicle and OFC-paroxetine groups 


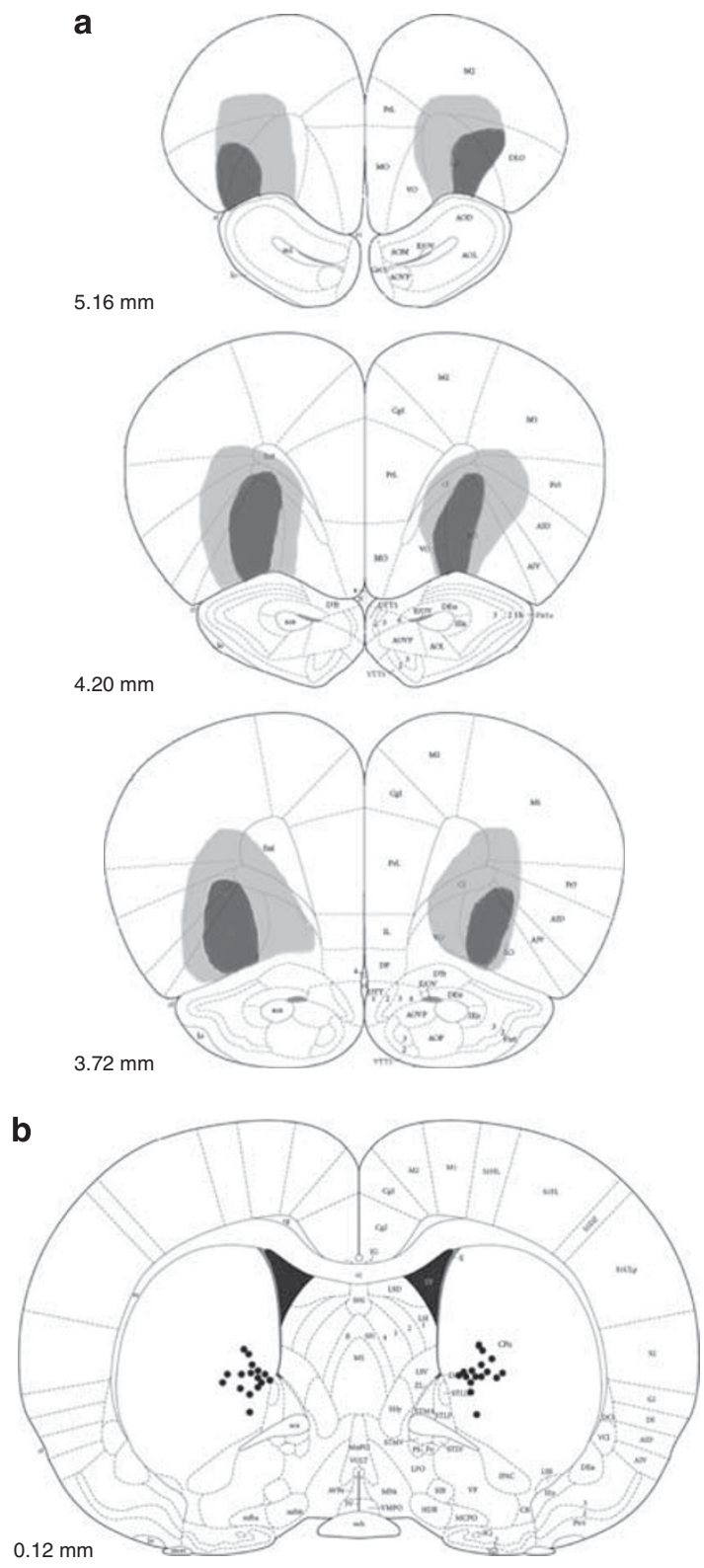

Figure 3 (a) Schematic reconstructions of coronal sections (Paxinos and Watson, 2005) showing the largest (gray shading) and smallest (black shading) extents of the OFC lesion in common for all rats in the lesion group. Numbers in each section indicate the A-P level anterior to the bregma. (b) A schematic representation of the injection cannulae placements in a coronal section (Paxinos and Watson, 2005) in the striatum of paroxetine-injected rats. The locations of the injector tips are represented by black dots. The number indicates the distance anterior to the bregma (Exp. 2).

$(p=0.048)$. A Lesion $\times$ Drug ANOVA performed on the number of ELP-C yielded no significant effects: Lesion, $\mathrm{F}(1,60)<0.01$, NS; Drug, $\mathrm{F}(1,60)=0.34$, NS; Lesion $\times$ Drug, $F(1,60)=2.31$, NS).

\section{Experiment 3: the Effects of Pre-Training Striatal Lesions in the PTSA and RE Procedures}

Anatomical. Figures $5 \mathrm{a}$ and $\mathrm{b}$ present a photomicrograph of a coronal section taken from a representative striatallesioned rat (a) and a sham-operated rat (b). Figure 5c presents a schematic reconstruction of the striatal lesion representing the minimal and the maximal extent of the damage in common for all rats in the lesion group. Most lesions were similar in size. Neuronal loss and accumulation of glia cells were evident in the ventromedial part of the dorsal striatum, excluding its most medial region. Four rats did not have lesions or lesions were off target ventrally and their results were excluded from the statistical analysis. The only visible damage in sham-operated rats was the cannulae track toward the target areas.

Behavioral. Magazine training: there were no differences between lesion and sham rats in the magazine training stage (data not shown; all F's $<1$ ). Lever-press training: there were no differences between lesion and sham rats in the acquisition of lever-pressing, and all rats, except two striatal-lesioned rats, readily acquired lever-pressing. On the last day of lever-press training, all rats achieved 40 completed trials, typically with no uncompleted trials and therefore with no ELP-U. From the second day of leverpress training, rats rarely pressed the NRL (data not shown; all F's $<1$ ). Signal attenuation: there were no differences between the lesion and sham groups in the extinction of the compound stimulus, as reflected in the number of collected trials, in either the rate of extinction or in the performance level at the end of this stage (data not shown; all F's $<1$ ). Three striatal-lesioned rats underwent an extra session of signal attenuation after failing to reach criterion on the third day. All rats attained criterion after this additional session.

Test. Figures $6 \mathrm{a}$ and $\mathrm{b}$ present the mean number of ELP-C and ELP-U in the test of the RE and PTSA procedures of striatal-lesioned and sham-operated rats. Striatal lesions had no effect on the number of ELP-C and of ELP-U in either the PTSA or the RE procedures (ELP-C: a Lesion $\times$ Procedure ANOVA yielded only a significant effect of Procedure, $\mathrm{F}(1,28)=6.05, p<0.021$; Lesion, $\mathrm{F}(1,28)<0.01$, NS; Lesion $\times$ Procedure, F $(1,28)=0.11$, NS; ELP-U: a Lesion $\times$ Procedure ANOVA yielded no significant results: Procedure, $\mathrm{F}(1,28)=0.09$, NS; Lesion, $\mathrm{F}(1,28)<0.01$, NS; Lesion $\times$ Procedure, $F(1,28)=0.79$, NS).

\section{Experiment 4: the Effects of Post-Training Striatal Inactivation in the PTSA and RE Procedures}

Anatomical. Figure 5d presents a photomicrograph of a coronal section taken through the striatum showing the cannula tract. Figure 5e presents a schematic reconstruction of cannulae placement in the striatum of striatal-inactivated rats. Seven rats were excluded because there was either no trace of the cannulae tips or the cannulae tips were misplaced. In all the other rats the cannulae tips were located within the striatal region innervated by the ventral and ventrolateral OFC. The only visible damage was the cannulae track toward the target areas.

Behavioral. There were no differences between the groups at the magazine training, lever-press training, and signal attenuation stages (data not shown; all F's $<1$ ). Four (three sham and one to-be-injected-with-muscimol) rats underwent an extra session of signal attenuation after 
Table 2 Summary of Experiments

\begin{tabular}{|c|c|c|c|c|c|}
\hline Experiment & Procedure & Number of rats in experiment & Number of rats excluded ${ }^{a}$ & Group & Final $\boldsymbol{n}$ per group \\
\hline \multirow[t]{2}{*}{ । } & Biochemistry & 16 & - & Orbital lesion & 8 \\
\hline & & & & Sham lesion & 8 \\
\hline \multirow{2}{*}{2} & & & after surgery & Orbital lesion, Vehicle & 17 \\
\hline & & & 7, statistical & Sham lesion, Drug & 15 \\
\hline \multirow{3}{*}{3} & & & 4 , statistical & SA, Sham & 9 \\
\hline & & & 3, histological & RE, Lesion & 7 \\
\hline & & & & RE, Sham & 8 \\
\hline 4 & $\mathrm{SA}$ and $\mathrm{RE}$ & 48 & 6 , died during or & SA, Inactivation & 9 \\
\hline
\end{tabular}

Abbreviation: SA, signal attenuation; RE, regular extinction.

aStatistical: rats were excluded if their score on at least one variable was more than 4 standard deviations above their group mean (calculated without the score of the deviant rat); Histological: rats were excluded if their histological analysis showed that either the lesion or cannulae were misplaced (see Results for details).
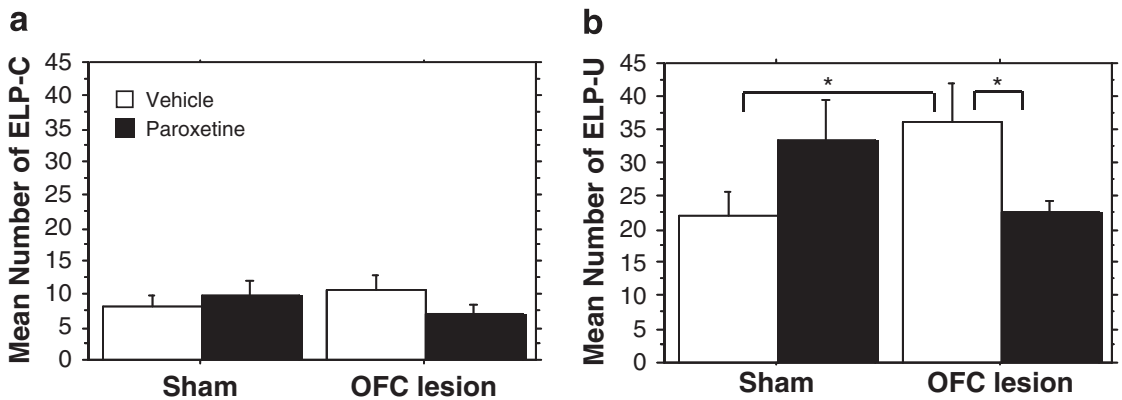

Figure 4 The mean and standard error of the mean number of (a) extra lever-presses that were followed by an attempt to collect a reward (ELP-C), and (b) extra lever-presses that were not followed by an attempt to collect a reward (ELP- $U$ ) in the test of intrastriatal vehicle-injected (empty bars) and paroxetine-injected (filled bars) rats sustaining either OFC or sham lesion (Experiment 2). $* 0<0.05$

failing to reach criterion on the third day. All rats attained criterion after this additional session.

Test. Figures $6 \mathrm{c}$ and $\mathrm{d}$ present the mean number of ELP-C and ELP-U in the test of the RE and PTSA procedures of rats whose striatum has been temporarily inactivated and of sham-operated rats. As can be seen, striatal inactivation led to a reduction in the number of ELP-C compared with sham rats in both the PTSA and RE procedures (an Inactivation $\times$ Procedure ANOVA yielded only a significant effect of inactivation, $\mathrm{F}(1,28)=29.84, p<0.0001$; Procedure, $\mathrm{F}(1,28)=1.61$, NS; and Inactivation $\times$ Procedure, $\mathrm{F}(1,28)=$ $0.56, \mathrm{NS})$, suggesting that striatal inactivation facilitates the extinction of lever-press responding. In contrast, the effects of striatal inactivation on ELP-U were procedure dependent, with striatal inactivation decreasing the number of ELP-U in rats undergoing PTSA but not affecting it in rats undergoing $\mathrm{RE}$ (an Inactivation $\times$ Procedure ANOVA yielded a significant Inactivation $\times$ Procedure interaction, $\mathrm{F}(1,28)=$ 6.46, $p<0.017$ and a significant effect of inactivation, $\mathrm{F}(1,28)=5.53, p<0.026$; Procedure, $\mathrm{F}(1,28)=0.57$, NS.
Post hoc LSD comparisons comparing the muscimol and sham groups within each procedure revealed a significant difference between the two groups in the PTSA procedure only, $p=0.0009$ ). This differential effect of striatal inactivation suggests that striatal inactivation exerted an anticompulsive effect in addition to the facilitation of extinction.

\section{DISCUSSION}

This study explored the role of the OFC-innervated striatum in compulsive lever-pressing in intact rats and in OFClesioned rats, and specifically tested the hypothesis that alterations in the striatal serotonergic system mediate the pro-compulsive effect of OFC lesions.

The results of Experiment 1 extended our previous observation that lesions to the ventrolateral and ventral regions of the OFC lead to changes in the striatal serotonergic system (Joel et al, 2005a), by showing that such lesions decrease the content of serotonin, dopamine, glutamate, and GABA in the striatum. These finding are in 
a



b


e

C
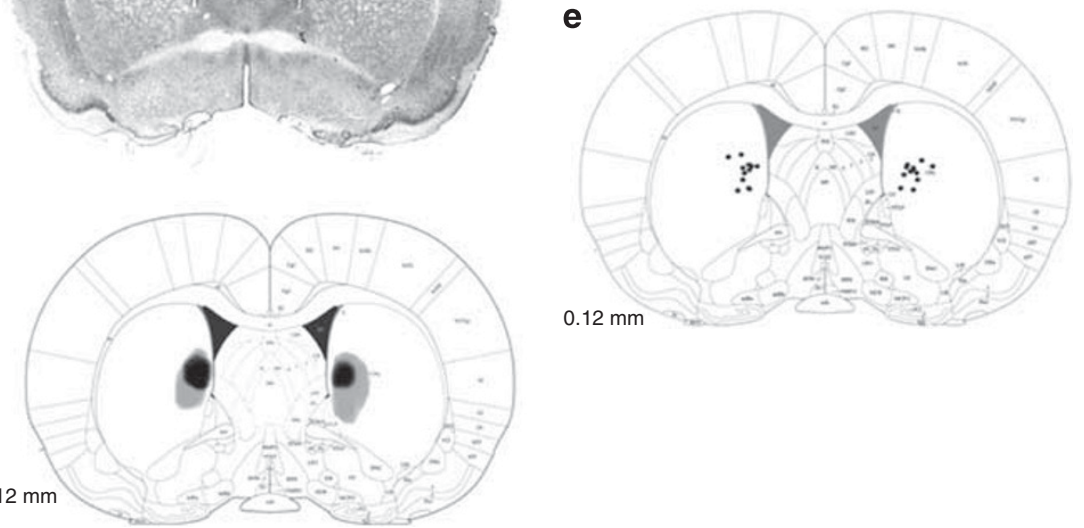

Figure 5 ( $a, b)$ A photomicrograph of a coronal section taken from a representative (a) striatal-lesioned rat and (b) sham-operated rat (Exp. 3). (c) A schematic reconstruction of a coronal section (Paxinos and Watson, 2005) showing the largest (gray shading) and smallest (black shading) extents of the striatal lesion in common for all rats in the lesion group. The number indicates the distance anterior to the bregma (Exp. 3). (d) A photomicrograph of a coronal section taken through the striatum of a representative cannula-implanted rat showing the cannula tract (Exp. 4). (e) A schematic representation of the injection cannulae placements in a coronal section (Paxinos and Watson, 2005) in the striatum of the striatal-inactivated rat. The locations of the injector tips are represented by black dots. The number indicates the distance anterior to the bregma (Exp. 4).
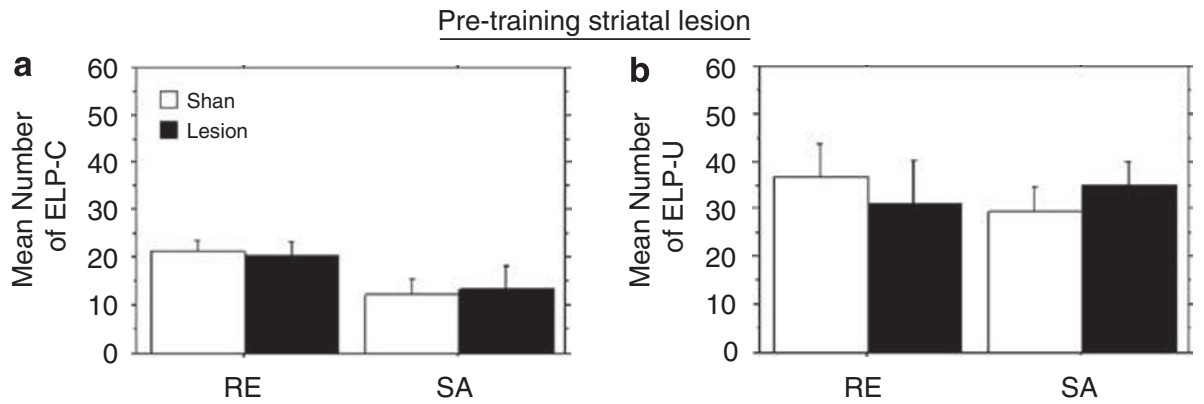

Post-training striatal inactivation
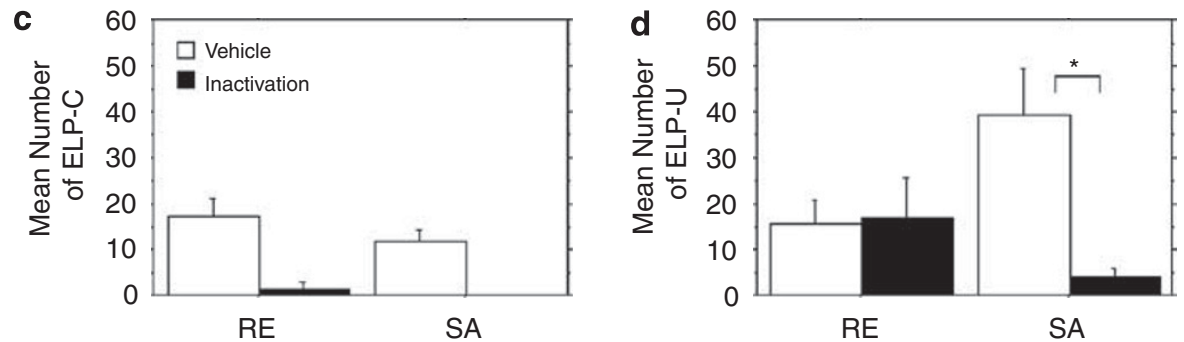

Figure 6 The mean and standard error of the mean number of $(a, c)$ extra lever-presses that were followed by an attempt to collect a reward (ELP-C) and $(b, d)$ extra lever-presses that were not followed by an attempt to collect a reward (ELP-U) in the test of the regular extinction (RE) or post-training signal attenuation (PTSA) procedures in (a, b) sham-operated and striatal-lesioned rats (Experiment 3 ) and (c, d) vehicle-injected and striatal-inactivated rats (Experiment 4). $*$ $p<0.001$ 
line with the known anatomy and functional relations between these neurotransmitter systems. Specifically, the OFC can affect serotonin and dopamine release in the striatum through its direct projections to the nuclei that provide serotonergic and dopaminergic input to the striatum (the dorsal raphe nucleus and the substantia nigra pars compacta and ventral tegmental area, respectively; Peyron et al, 1998; Porrino and Goldman-Rakic, 1982; Sesack et al, 1989; Vertes, 1991). In addition, the OFC provides glutamatergic input to the striatum, and glutamate has been shown to affect striatal serotonin and dopamine release and turnover (Abellan et al, 2000; Cartmell et al, 2000; Healy and Meador-Woodruff, 1999). Finally, there are complex interactions between serotonin and dopamine (for review see Di Giovanni et al, 2008; Di Matteo et al, 2008).

Another novel finding of this study is that the increase in compulsive lever-pressing following lesions to the OFC is blocked by administration of the SSRI paroxetine into the OFC-innervated striatum (Experiment 2). It should be noted that the effect of paroxetine was restricted to OFC lesioninduced compulsive lever-pressing, as intrastriatal administration of this drug did not affect this form of behavior in sham-operated rats and did not affect ELP-C in both sham and OFC-lesioned rats. The present finding supports the possibility that changes in the striatal serotonergic system mediate the increased compulsivity brought about by the OFC lesion. Moreover, it supports our recent hypothesis that a decrease in striatal serotonin and/or dopamine provides a final common pathway by which different brain pathologies lead to a pro-compulsive state. This hypothesis has been raised on the basis of the observation that similarly to lesions to the OFC, lesions to the subthalamic nucleus increase compulsive lever-pressing and decrease dopamine and serotonin (but not glutamate and GABA) in the striatum (Winter et al, 2008a). It is also noteworthy that pharmacological inactivation and high-frequency stimulation of the subthalamic nucleus, that exert an anticompulsive effect in the signal attenuation model (Klavir et al, 2009), have been reported to increase dopamine levels in the striatum (Bruet et al, 2001; Meissner et al, 2001; Lee et al, 2006). To the best of our knowledge there are no studies that assessed the effects of these manipulations on striatal serotonin.

The possibility that alterations in striatal serotonin and/or dopamine are involved in compulsive behavior is in agreement with many lines of evidence implicating these systems in the pathophysiology of OCD and in the response to treatment. Specifically, the findings that serotonin reuptake inhibitors are effective in alleviating obsessions and compulsions in patients have directed much attention to the involvement of the serotonergic system in OCD (for review see Sasson and Zohar, 1996; Stein, 2000), with more recent studies implicating specific serotonin receptors (most notably 5-HT1a, 5-HT2a, and 5-HT2c) in the pathophysiology of OCD and in the response to treatment (for review see El Mansari and Blier, 2006; Goddard et al, 2008; Van Oekelen et al, 2003). Abnormalities of the dopaminergic system have been implicated in OCD on the basis of several lines of clinical and preclinical evidence (for review see Denys et al, 2004), including changes in OC symptoms following the administration of amphetamine and cocaine to OCD patients (Insel et al, 1983; Leonard and Rapoport, 1987; McDougle et al, 1989), and the surplus therapeutic benefits obtained with co-administration of SSRIs and dopaminergic blockers (McDougle et al, 1994; Sasson and Zohar, 1996; Saxena et al, 1996). Involvement of the striatum (mainly the caudate nucleus) in OCD has been derived mainly from functional imaging studies revealing higher metabolic activity in this region in OCD patients compared to healthy controls, and metabolic normalization following a successful behavioral or SSRI treatment (Baxter et al, 1992; Saxena et al, 1999). There is, however, little direct evidence for abnormalities of striatal dopamine and/or serotonin in OCD. One such piece of evidence comes from recent reports of increased density of the dopamine transporter in the striatum of OCD patients (Kim et al, 2003; van der Wee et al, 2004). Although several studies have assessed the density of the serotonergic transporter in OCD patients, none reported changes in this protein in the striatum (for review see Goddard et al, 2008).

In summary, the results obtained with OFC-lesioned rats suggest that changes in serotonin level in the OFC-innervated striatum are responsible for OFC lesion-induced increased compulsivity. It should be noted, however, that we do not have evidence that the change in serotonin level was confined to the OFC-innervated striatum, as the assessment of neurotransmitter content was not restricted to this striatal region but rather included the entire anterior and posterior caudate-putamen. Similarly, we have no evidence that paroxetine administration is effective only when injected into the OFC-innervated striatum, because we have not tested the effects of paroxetine administration into other striatal regions.

Experiments 3 and 4 tested the role of the striatum in intact rats. Experiment 3 found that pretraining lesions to the OFC-innervated striatum did not affect compulsive lever-pressing. This finding suggests that in a striatallesioned brain compulsive lever-pressing is mediated by other brain regions. In contrast, pharmacological inactivation of the OFC-innervated striatum made just before the test stage exerted an anticompulsive effect, suggesting that this striatal region may be involved in the expression of compulsive responding not only in OFC-lesioned rats but also in intact animals.

In the light of this latter result, the finding that intrastriatal administration of paroxetine had no effect on compulsive responding in sham-operated rats (Experiment 2) seems surprising. One interpretation of this lack of effect is that whereas the striatal serotonergic system is involved in mediating OFC lesion-induced compulsive responding, it is not involved in mediating compulsive responding in nonlesioned rats. An alternative interpretation is that intrastriatal administration of paroxetine was ineffective in sham rats because the dose used was too low. Specifically, it is possible that although $0.75 \mu \mathrm{g} / \mu \mathrm{l}$ paroxetine exerted an anticompulsive effect in OFC-lesioned rats, this dose was not sufficient in the nonlesioned brain because, as we have found (this study and Joel et al, 2005a), lesions to the OFC result in marked changes in the striatal serotonergic system, including an increase in the density of the serotonin transporter (Joel et al, 2005a). It is therefore possible that higher doses of paroxetine are needed to induce an anticompulsive effect in sham (or intact) rats. 
To the best of our knowledge, there are no studies that have tested the behavioral effects of manipulations confined to the striatal region targeted in this study. There are, however, studies that tested the role of the medial striatum, and the region manipulated included also the region targeted in this study. The striatal lesions in these studies typically comprise also a more dorsal region and/or the most medial region of the striatum (which are spared in this study) (Brown and Robbins, 1989; Devan and White, 1999; Rogers et al, 2001; Yin et al, 2004). Below we compare the present results on the effects of striatal manipulations on the acquisition and extinction of magazine approach (in the magazine-training and signal attenuation stages, respectively) and lever-pressing (in the lever-press training and test stages, respectively) as well as on compulsive responding (during the test) to previous studies. We refer to the striatal region manipulated in this study as ventromedial caudate-putamen, so that it is clear that we refer to the ventromedial part of the dorsal striatum and not to the nucleus accumbens.

The results of Experiment 3 show that pre-training lesions to the ventromedial caudate-putamen do not affect the acquisition and extinction of magazine approach, nor the acquisition and extinction of lever-press responding. Studies testing the effects of pre-training lesions to the medial striatum found no effect on the acquisition of magazine approach (Rogers et al, 2001; Yin et al, 2004, 2005). The effects of medial striatal lesions on the acquisition and extinction of lever-pressing are not clear, as there are reports of both higher (Yin et al, 2004) and lower (Yin et al, 2005) rates of lever-press responding at the end of lever-press training and during extinction, in striatallesioned rats compared with sham rats. The differences between studies may reflect differences in the schedule of reinforcement used, as Yin et al (2004) used variable interval schedule, Yin et al (2005) used random ratio schedule, and this study (which found no effect) used a discrete trial procedure, as well as differences in the exact location of the lesion, as Yin et al (2005) found differences in the effects of anterior $v s$ posterior medial striatal lesions.

Experiment 4 revealed that inactivation of the ventromedial caudate-putamen before the test stage facilitated the extinction of lever-press responding and decreased compulsive lever-pressing. There are no previous reports on the effects of inactivation of the ventromedial or medial caudate-putamen on extinction. Yin et al (2005) found that post-training lesions of the anterior (but not posterior) medial striatum increased the rate of lever-press responding during extinction, an effect opposite to that reported here. As noted earlier, this discrepancy may reflect differences in the schedule of reinforcement used (random ratio $v s$ discrete trial), the exact location of the manipulation, as well as the type of manipulation (lesion $v s$ inactivation).

There are no studies that assessed the effects of striatal inactivation in rat models of OCD. Yin et al (2006) have recently suggested, however, that insensitivity to changes in response-outcome contingency, which is a hallmark of habitual responding, may serve to model compulsive responding, as the latter has been attributed to the potentiation of the habit system. These authors have found that inactivation of the dorsolateral striatum resulted in increased sensitivity to changes in the response-outcome contingency, and suggested that this may reflect an anticompulsive effect. Other studies have found that posttraining lesion and inactivation of the medial striatum increased the emission of premature and perseverative responses in different procedures (Brown and Robbins, 1989; Dobrossy and Dunnett, 1997; Brasted et al, 1998; Rogers et al, 2001), suggesting that such manipulations have a pro-impulsive and a pro-compulsive effect, respectively (Rogers et al, 2001). The present finding that inactivation of the striatum exerted an anticompulsive effect provides another demonstration that impulsivity and compulsivity may be separable in terms of the subserving neural systems (Winstanley et al, 2004; Boulougouris et al, 2008), and further suggests that perseverative responding and compulsive responding are not identical.

To summarize, the results of the present study strongly implicate the striatal region innervated by the ventral and ventrolateral $\mathrm{OFC}$ in the expression of compulsive leverpressing in both intact rats and rats sustaining a lesion to the OFC. The possibility that the striatum is mediating compulsive lever-pressing is in line with evidence implicating the striatum in the pathophysiology of OCD (for review see Stein, 2000) and with views on the central role of the striatum in habitual and compulsive behavior (Graybiel, 1998; Yin et al, 2004; Balleine, 2005; Everitt and Robbins, 2005; Bailey and Mair, 2006; Packard et al, 1989), although the latter have typically been related to the lateral, rather than medial, striatum. Furthermore, although the extrapolation from an animal model to the clinical condition is problematic and should be made with great caution, the results of this study support the possibility that in a subpopulation of OCD patients a primary pathology of the OFC leads to a dysregulation of the striatal serotonergic system that is manifested in compulsive behavior, and that antiobsessional/anticompulsive drugs exert their effects, in these patients, by normalizing the dysfunctional striatal serotonergic system (Joel et al, 2005a).

\section{ACKNOWLEDGEMENTS}

This work was supported by the National Institute for Psychobiology in Israel - Founded by the Charles E Smith Family (Grant no. 2004-5-13) and by the Israel Science Foundation (Grant no. 942/01-1).

\section{DISCLOSURE}

The authors declare no conflict of interest.

\section{REFERENCES}

Abellan MT, Martin-Ruiz R, Artigas F (2000). Local modulation of the 5-ht release in the dorsal striatum of the rat: an in vivo microdialysis study. Eur Neuropsychopharmacol 10: 455-462.

Aouizerate B, Guehl D, Cuny E, Rougier A, Bioulac B, Tignol J et al (2004). Pathophysiology of obsessive-compulsive disorder: a necessary link between phenomenology, neuropsychology, imagery and physiology. Prog Neurobiol 72: 195-221. 
Bailey KR, Mair RG (2006). The role of striatum in initiation and execution of learned action sequences in rats. J Neurosci 26: 1016-1025.

Balleine BW (2005). Neural bases of food-seeking: affect, arousal and reward in corticostriatolimbic circuits. Physiol Behav 86: 717-730.

Baxter Jr LR, Schwartz JM, Bergman KS, Szuba MP, Guze BH, Mazziotta JC et al (1992). Caudate glucose metabolic rate changes with both drug and behavior therapy for obsessivecompulsive disorder. Arch Gen Psychiatry 49: 681-689.

Benkelfat C, Nordahl TE, Semple WE, King AC, Murphy DL, Cohen RM (1990). Local cerebral glucose metabolic rates in obsessivecompulsive disorder. Patients treated with clomipramine. Arch Gen Psychiatry 47: 840-848.

Berendse HW, Galis-de Graaf Y, Groenewegen HJ (1992). Topographical organization and relationship with ventral striatal compartments of prefrontal corticostriatal projections in the rat. J Comp Neurol 316: 314-347.

Boulougouris V, Glennon JC, Robbins TW (2008). Dissociable effects of selective 5-ht2a and 5-ht2c receptor antagonists on serial spatial reversal learning in rats. Neuropsychopharmacology 33: 2007-2019.

Brasted PJ, Dobrossy MD, Robbins TW, Dunnett SB (1998). Striatal lesions produce distinctive impairments in reaction time performance in two different operant chambers. Brain Res Bull 46: 487-493.

Breiter HC, Rauch SL, Kwong KK, Baker JR, Weisskoff RM, Kennedy DN et al (1996). Functional magnetic resonance imaging of symptom provocation in obsessive-compulsive disorder. Arch Gen Psychiatry 53: 595-606.

Brown VJ, Robbins TW (1989). Elementary processes of response selection mediated by distinct regions of the striatum. J Neurosci 9: 3760-3765.

Bruet N, Windels F, Bertrand A, Feuerstein C, Poupard A, Savasta $M$ (2001). High frequency stimulation of the subthalamic nucleus increases the extracellular contents of striatal dopamine in normal and partially dopaminergic denervated rats. J Neuropathol Exp Neurol 60: 15-24.

Cartmell J, Salhoff CR, Perry KW, Monn JA, Schoepp DD (2000). Dopamine and 5-ht turnover are increased by the mglu2/3 receptor agonist ly379268 in rat medial prefrontal cortex, nucleus accumbens and striatum. Brain Res 887: 378-384.

Cottraux J, Gerard D, Cinotti L, Froment JC, Deiber MP, Le Bars D et al (1996). A controlled positron emission tomography study of obsessive and neutral auditory stimulation in obsessivecompulsive disorder with checking rituals. Psychiatry Res 60: 101-112.

Coutureau E, Killcross S (2003). Inactivation of the infralimbic prefrontal cortex reinstates goal-directed responding in overtrained rats. Behav Brain Res 146: 167-174.

Denys D, Zohar J, Westenberg HGM (2004). The role of dopamine in obsessive-compulsive disorder: preclinical and clinical evidence. J Clin Psychiatry 65: 11-17.

Devan BD, White NM (1999). Parallel information processing in the dorsal striatum: relation to hippocampal function. J Neurosci 19: 2789-2798.

Di Giovanni G, Di Matteo V, Pierucci M, Esposito E (2008). Serotonin-dopamine interaction: electrophysiological evidence. Prog Brain Res 172: 45-71.

Di Matteo V, Di Giovanni G, Pierucci M, Esposito E (2008). Serotonin control of central dopaminergic function: focus on in vivo microdialysis studies. Prog Brain Res 172: 7-44.

American Psychiatric Association Diagnostic and Statistical Manual of Mental Disorders, 4th ed, (1994) American Psychiatric Association: Washington, DC.

Dobrossy MD, Dunnett SB (1997). Unilateral striatal lesions impair response execution on a lateralised choice reaction time task. Behav Brain Res 87: 159-171.
Dolberg OT, Iancu I, Sasson Y, Zohar J (1996). The pathogenesis and treatment of obsessive-compulsive disorder. Clin Neuropharmacol 19: 129-147.

Edeline JM, Hars B, Hennevin E, Cotillon N (2002). Muscimol diffusion after intracerebral microinjections: a reevaluation based on electrophysiological and autoradiographic quantifications. Neurobiol Learn Mem 78: 100-124.

El Mansari M, Blier P (2006). Mechanisms of action of current and potential pharmacotherapies of obsessive-compulsive disorder. Prog Neuropsychopharmacol Biol Psychiatry 30: 362-373.

Everitt BJ, Robbins TW (2005). Neural systems of reinforcement for drug addiction: from actions to habits to compulsion. Nat Neurosci 8: 1481-1489.

Felice LJ, Felice JD, Kissinger PT (1978). Determination of catecholamines in rat brain parts by reverse-phase ion-pair liquid chromatography. J Neurochem 31: 1461-1465.

Flaisher-Grinberg S, Klavir O, Joel D (2008). The role of 5-HT2a and 5 -HT2c receptors in the signal attenuation rat model of obsessive compulsive disorder. Int J Neuropsychopharmacol 11: 811-825.

Friedlander L, Desrocher M (2006). Neuroimaging studies of obsessive-compulsive disorder in adults and children. Clin Psychol Rev 26: 32-49.

Goddard AW, Shekhar A, Whiteman AF, NcDougle CJ (2008). Serotonergic mechanisms in the treatment of obsessive-compulsive disorder. Drug Discov Today 13: 325-332.

Graybiel AM (1998). The basal ganglia and chunking of action repertoires. Neurobiol Learn Mem 70: 119-136.

Healy DJ, Meador-Woodruff JH (1999). Ionotropic glutamate receptor modulation of 5-ht6 and 5-ht7 mRNA expression in rat brain. Neuropsychopharmacology 21: 341-351.

Insel TR (1992). Toward a neuroanatomy of obsessive-compulsive disorder. Arch Gen Psychiatry 49: 739-744.

Insel TR, Hamilton JA, Guttmacher LB, Murphy DL (1983). D-amphetamine in obsessive-compulsive disorder. Psychopharmacology 80: 231-235.

Izaki Y, Maruki K, Hori K, Nomura M (2001). Effects of rat medial prefrontal cortex temporal inactivation on a delayed alternation task. Neurosci Lett 315: 129-132.

Joel D (2006). The signal attenuation rat model of obsessivecompulsive disorder: a review. Psychopharmacology (Berl) 186: 487-503.

Joel D, Avisar A (2001). Excessive lever pressing following post-training signal attenuation in rats: a possible animal model of obsessive compulsive disorder? Behav Brain Res 123: 77-87.

Joel D, Avisar A, Doljansky J (2001). Enhancement of excessive lever-pressing after post-training signal attenuation in rats by repeated administration of the d1 antagonist sch 23390 or the $\mathrm{d} 2$ agonist quinpirole, but not the $\mathrm{d} 1$ agonist skf 38393 or the $\mathrm{d} 2$ antagonist haloperidol. Behav Neurosci 115: 1291-1300.

Joel D, Ben-Amir E, Doljansky J, Flaisher S (2004). 'Compulsive' lever-pressing in rats is attenuated by the serotonin re-uptake inhibitors paroxetine and fluvoxamine but not by the tricyclic antidepressant desipramine or the anxiolytic diazepam. Behav Pharmacol 15: 241-252.

Joel D, Doljansky J (2003). Selective alleviation of compulsive lever-pressing in rats by $\mathrm{d} 1$, but not $\mathrm{d} 2$, blockade: possible implications for the involvement of $\mathrm{d} 1$ receptors in obsessivecompulsive disorder. Neuropsychopharmacology 28: 77-85.

Joel D, Doljansky J, Roz N, Rehavi M (2005a). Role of the orbital cortex and of the serotonergic system in a rat model of obsessive compulsive disorder. Neuroscience 130: 25-36.

Joel D, Doljansky J, Schiller D (2005b). 'Compulsive' lever pressing in rats is enhanced following lesions to the orbital cortex, but not to the basolateral nucleus of the amygdala or to the dorsal medial prefrontal cortex. Eur J Neurosci 21: 2252-2262. 
Joel D, Klavir O (2006). The effects of temporary inactivation of the orbital cortex in the signal attenuation rat model of obsessive compulsive disorder. Behav Neurosci 120: 976-983.

Kim CH, Koo MS, Cheon KA, Ryu YH, Lee JD, Lee HS (2003). Dopamine transporter density of basal ganglia assessed with [123I]IPT SPET in obsessive-compulsive disorder. Eur J Nucl Med Mol Imaging 30: 1637-1643.

Klavir O, Flash S, Winter C, Joel D (2009). High frequency stimulation and pharmacological inactivation of the subthalamic nucleus reduces 'compulsive' lever-pressing in rats. Exp Neurol 215: 101-109.

Lee $\mathrm{KH}$, Blaha CD, Harris BT, Cooper S, Hitti FL, Leiter JC et al (2006). Dopamine efflux in the rat striatum evoked by electrical stimulation of the subthalamic nucleus: potential mechanism of action in Parkinson's disease. Eur J Neurosci 23: 1005-1014.

Leonard HL, Rapoport JL (1987). Relief of obsessive-compulsive symptoms following stimulants. Biol Psychiatry 20: 1332-1337.

McDougle CJ, Goodman WK, Delgado PL, Price LH (1989). Pathophysiology of obsessive-compulsive disorder. Am J Psychiatry 146: 1350-1351.

McDougle CJ, Goodman WK, Leckman JF, Lee NC, Heninger GR, Price LH (1994). Haloperidol addition in fluvoxamine-refractory obsessive-compulsive disorder. A double-blind, placebo-controlled study in patients with and without tics. Arch Gen Psychiatry 51: 302-308.

McGuire PK, Bench CJ, Frith CD, Marks IM, Frackowiak RS, Dolan RJ (1994). Functional anatomy of obsessive-compulsive phenomena. Br J Psychiatry 164: 459-468.

Meissner W, Reum T, Paul G, Harnack D, Sohr R, Morgenstern R et al (2001). Striatal dopaminergic metabolism is increased by deep brain stimulation of the subthalamic nucleus in 6-hydroxydopamine lesioned rats. Neurosci Lett 303: 165-168.

Otto MW (1992). Normal and abnormal information processing. A neuropsychological perspective on obsessive compulsive disorder. Psychiatr Clin North Am 15: 825-848.

Packard MG, Hirsh R, White NM (1989). Differential effects of fornix and caudate nucleus lesions on two radial maze tasks: evidence for multiple memory systems. J Neurosci 9: 1465-1472.

Paxinos GW, Watson C (2005). The Rat Brain in Stereotaxic Coordinates. Academic Press: Oxford, UK.

Peyron C, Petit JM, Rampon C, Jouvet M, Luppi PH (1998). Forebrain afferents to the rat dorsal raphe nucleus demonstrated by retrograde and anterograde tracing methods. Neuroscience 82: 443-468.

Piccinelli M, Pini S, Bellantuono C, Wilkinson G (1995). Efficacy of drug treatment in obsessive-compulsive disorder. A metaanalytic review. Br J Psychiatry 166: 424-443.

Piepponen TP, Skujins A (2001). Rapid and sensitive step gradient assays of glutamate, glycine, taurine and gamma-aminobutyric acid by high-performance liquid chromatography-fluorescence detection with $o$-phthalaldehyde-mercaptoethanol derivatization with an emphasis on microdialysis samples. J Chromatogr B Biomed Sci Appl 757: 277-283.

Porrino LJ, Goldman-Rakic PS (1982). Brainstem innervation of prefrontal and anterior cingulate cortex in the rhesus monkey revealed by retrograde transport of hrp. J Comp Neurol 205: 63-76.

Rauch SL, Jenike MA, Alpert NM, Baer L, Breiter HC, Savage CR et al (1994). Regional cerebral blood flow measured during symptom provocation in obsessive-compulsive disorder using oxygen 15-labeled carbon dioxide and positron emission tomography. Arch Gen Psychiatry 51: 62-70.

Rogers RD, Baunez C, Everitt BJ, Robbins TW (2001). Lesions of the medial and lateral striatum in the rat produce differential deficits in attentional performance. Behav Neurosci 115: 799-811.
Samson HH, Chappell A (2001). Muscimol injected into the medial prefrontal cortex of the rat alters ethanol self-administration. Physiol Behav 74: 581-587.

Sasson Y, Zohar J (1996). New developments in obsessivecompulsive disorder research: implications for clinical management. Int Clin Psychopharmacol 11: 3-12.

Saxena S, Brody AL, Maidment KM, Dunkin JJ, Colgan M, Alborzian S et al (1999). Localized orbitofrontal and subcortical metabolic changes and predictors of response to paroxetine treatment in obsessive-compulsive disorder. Neuropsychopharmacology 21: 683-693.

Saxena S, Brody AL, Schwartz JM, Baxter LR (1998). Neuroimaging and frontal-subcortical circuitry in obsessive-compulsive disorder. Br J Psychiatry Suppl 26-37.

Saxena S, Wang D, Bystritsky A, Baxter LR (1996). Risperidone augmentation of SRI treatment for refractory obsessive-compulsive disorder. J Clin Psychiatry 57: 303-306.

Sesack SR, Deutch AY, Roth RH, Bunney BS (1989). Topographical organization of the efferent projections of the medial prefrontal cortex in the rat: an anterograde tract-tracing study with phaseolus vulgaris leucoagglutinin. J Comp Neurol 290: 213-242.

Schilman EA, Uylings HBM, Galis-de Graaf Y, Daphna J, Groenewegen HJ (2008). The orbital cortex in rats topographically projects to central parts of the caudate-putamen complex. Neurosci Lett 432: 40-45.

Sperk G (1982). Simultaneous determination of serotonin, 5-hydroxindoleacetic acid, 3,4-dihydroxyphenylacetic acid and homovanillic acid by high performance liquid chromatography with electrochemical detection. $J$ Neurochem 38: 840-843.

Sperk G, Berger M, Hortnagl H, Hornykiewicz O (1981). Kainic acid-induced changes of serotonin and dopamine metabolism in the striatum and substantia nigra of the rat. Eur J Pharmacol 74: 279-286.

Stein DJ (2000). Neurobiology of the obsessive-compulsive spectrum disorders. Biol Psychiatry 47: 296-304.

Swedo SE, Pietrini P, Leonard HL, Schapiro MB, Rettew DC, Goldberger EL et al (1992). Cerebral glucose metabolism in childhood-onset obsessive-compulsive disorder. Revisualization during pharmacotherapy. Arch Gen Psychiatry 49: 690-694.

Szechtman H, Woody E (2004). Obsessive-compulsive disorder as a disturbance of security motivation. Psychol Rev 111: 111-127.

Van De Werd HJ, Uylings HB (2008). The rat orbital and agranular insular prefrontal cortical areas: a cytoarchitectonic and chemoarchitectonic study. Brain Struct Funct 212: 387-401.

van der Wee NJ, Stevens H, Hardeman JA, Mandl RC, Denys DA, van Megen $\mathrm{HJ}$ et al (2004). Enhanced dopamine transporter density in psychotropic-naive patients with obsessive-compulsive disorder shown by [123I] \{beta\}-CIT SPECT. Am J Psychiatry 161: 2201-2206.

Van Oekelen D, Luyten WH, Leysen JE (2003). 5-HT2A and 5-HT2C receptors and their atypical regulation properties. Life Sci 72: 2429-2449.

Vertes RP (1991). A PHA-l analysis of ascending projections of the dorsal raphe nucleus in the rat. J Comp Neurol 313: 643-668.

Winstanley CA, Theobald DE, Dalley JW, Glennon JC, Robbins TW (2004). 5-HT2a and 5-HT2c receptor antagonists have opposing effects on a measure of impulsivity: interactions with global 5-HT depletion. Psychopharmacology (Berl) 176: 376-385.

Winter C, Djodari-Irani A, Sohr R, Morgenstern R, Feldon J, Juckel $\mathrm{G}$ et al (2008a). Prenatal immune activation leads to multiple changes in basal neurotransmitter levels in the adult brain: implications for brain disorders of neurodevelopmental 
origin such as schizophrenia. Int J Neuropsychopharmacol 12: 513-524.

Winter C, Flash S, Klavir O, Klein J, Sohr R, Joel D (2008b). The role of the subthalamic nucleus in 'compulsive' behavior in rats. Eur J Neurosci 27: 1902-1911.

Yin HH, Knowlton BJ, Balleine BW (2004). Lesions of dorsolateral striatum preserve outcome expectancy but disrupt habit formation in instrumental learning. Eur J Neurosci 19: 181-189.

Yin HH, Knowlton BJ, Balleine BW (2006). Inactivation of dorsolateral striatum enhances sensitivity to changes in the action-outcome contingency in instrumental conditioning. Behav Brain Res 166: 189-196.

Yin HH, Ostlund SB, Knowlton BJ, Balleine BW (2005). The role of the dorsomedial striatum in instrumental conditioning. Eur J Neurosci 22: 513-523.

Zohar J, Insel TR (1987). Obsessive-compulsive disorder: psychobiological approaches to diagnosis, treatment, and pathophysiology. Biol Psychiatry 22: 667-687.

Zohar J, Zohar-Kadouch RC, Kindler S (1992). Current concepts in the pharmacological treatment of obsessive-compulsive disorder. Drugs 43: 210-218. 